\title{
La relación entre algunos modelos de participación popular ruso, cubano y venezolano (Estudio histórico comparativo)
}

María Fátima Pinho De Oliveira ${ }^{1}$

\section{Resumen}

La investigación tuvo como objetivo presentar un estudio histórico comparativo sobre la forma de participación protagónica de la sociedad como parte de un modelo de gestión dentro de la sociedad y vinculada con el Estado. En Venezuela se crearon los Consejos Comunales y se le dio rango legal con una ley publicada en 2006; pero, este estudio ha indagado sus orígenes históricos, tomándose la figura de los Soviets de Rusia y los Consejos Populares de Cuba como antecedentes de su creación en Venezuela. El enfoque metodológico fue documental. En conclusión, los soviets, surgieron espontáneamente entre los obreros en huelga durante 1905, como órganos de coordinación de la lucha gremial (comisiones obreras) por fábricas, encargadas de dirigir la huelga; los Consejos Populares de Cuba actúan como figuras fiscalizadoras y como piezas importantes en la participación de la comunidad en la solución de sus problemas, y los Consejos Comunales de Venezuela son órganos de participación que realizan y promueven la realización de actividades de interés general comunitario, llegando algunos a administrar recursos públicos, estando obligados a llevar registros y a rendir cuentas de ese manejo del patrimonio público.

Palabras clave: historia; consejos comunales; soviet; consejo popular.

\section{Summary}

This research aimed to present a comparative historical study on the form of the society protagonist participation as part of a management model within society and linked with the state. In Venezuela they created the Community Councils and they were given legal status with a law published in 2006; but this study has inquired its historical origins taking the figure of the Russia Soviets and the Popular Councils of Cuba as an antecedent of its creation in Venezuela. The methodological approach used was documentary. In conclusion, the soviets emerge spontaneously among the workers that were on strike during 1905, as coordinating bodies of the union struggle (workers' commissions) for factories and responsible for leading the strike; the Popular Councils of Cuba act as audit figures as well as important pieces on the participation of the community in solving its problems. On the other side, the Community Councils

1 Abogado, Magister en Derecho, Docente Investigadora de la Universidad Simón Bolívar. Correo: mpinho@usb.ve 
of Venezuela are participative bodies that perform and promote the implementation of activities of general interest of the community, some of which have reached to manage public resources, while being required to keep records and give account for the use of public property.

Keywords: History; community councils; Soviet; popular council.

\section{Introducción}

El estudio se enmarca dentro de una figura como lo es la participación, etimológicamente proviene del latín "Partem capere" que se traduce en "tomar una parte" o "tomar parte"; en sentido técnico la participación ciudadana es comprendida como un proceso social, continuo y dinámico, por medio del cual los miembros de una comunidad a través de mecanismos establecidos y organizaciones legítimas en las cuales se encuentren representados todos los miembros de la comunidad, en tanto es un poco complicado dialogar con todos y cada uno de los miembros; los mismos deciden, aportan y participan en la realización del bien común; también puede traducirse en la actuación de los ciudadanos en las actividades públicas, todo esto para hacer prevalecer tanto sus intereses sociales así como para defender y garantizar los derechos colectivos o difusos, a través de mecanismos (estructuras y procesos) idóneos por medio de los cuales la ciudadanía es tomada en cuenta en la toma de decisiones por parte de la administración pública en materias que de manera directa le afectan, abarcando incluso etapas anteriores y posteriores a la toma de decisiones en sí, como podrían ser la consulta, resolución, votación y ejecución de esas decisiones.

La participación ciudadana puede también ser considerada como forma estratégica usada para activar o reactivar las relaciones entre el gobierno y la sociedad, en aras de afianzar el sistema democrático como forma de gobierno, la misma ofrece elementos eficientes y eficaces para democratizar y mejorar la sociedad, dando así, igualmente, legitimidad al sistema democrático para que los resultados de la participación ciudadana sean abarcar áreas relacionadas a la formulación, ejecución y control de la gestión pública.

Como herramienta fortalecedora del régimen democrático la participación ciudadana contribuye con el desarrollo de un clima general de solidaridad, responsabilidad y trabajo afianzando de igual forma valores de consciencia ciudadana, de allí que cuando el Estado estimula y crea espacios de participación activa, consciente, libre, representativa, igualitaria, responsable y eficaz, donde se democratizan las tomas de decisiones, al mismo tiempo se desarrollen instituciones con sentido social y de bien común que responden a las necesidades de la población. 


\section{CIENCIAS SOCIALES}

En este sentido las formas de participación son variadas y han tenido una compleja evolución para llegar a lo que hoy en día se conoce, por ello el presente estudio abarca tres situaciones puntuales sobre esas formas de agrupación de la sociedad para lograr los fines que se trazan.

\section{Revisión de literatura}

\section{La revolución Rusa de 1905: El nacimiento de los soviets}

Surgidos durante la revolución de 1905, los soviets fueron una creación genuina de los obreros en lucha. Cierto, en la mayoría de los procesos revolucionarios anteriores habían existido consejos democráticos de representantes de las masas: los hubo durante la primera Revolución inglesa, en las Revoluciones francesas de 1789 y de 1848, y también en la Comuna de París.

Sin embargo, no existía en la Rusia de principios del siglo XX ninguna tradición que apuntara a una forma política tal. Existían sí sólidas costumbres de organización y deliberación colectivas, por ejemplo en las comunas campesinas. Pero ninguna de ellas puede tomarse como antecedente directo de los soviets.

Los soviets tal como se conocieron, surgieron espontáneamente entre los obreros en huelga durante 1905, inicialmente no como órganos políticos sino de coordinación de la lucha gremial. Nacieron bajo la forma de "comisiones obreras" por fábricas, encargadas de dirigir la huelga y representar a los huelguistas en las negociaciones con la patronal, en un contexto en el que los sindicatos o los partidos tenían escasa presencia.

El primer soviet de 1905 surgió en la zona textil de Ivanovo-Voznesensk (Moscú), a partir de una junta de representantes de los huelguistas que se encargó de establecer una lista de reivindicaciones económicas.

El soviet se dio como misión dirigir la huelga y negociar con la patronal. Pero las soluciones requeridas para el conflicto no aparecían, y comenzaron a aparecer en el soviet las primeras reivindicaciones propiamente políticas (por ejemplo, la convocatoria a una asamblea constituyente). Remotamente estaba el soviet de proponerse la toma del poder, y de hecho terminó disolviéndose desbordado por las presiones de las bases.

Aunque tras 1905 se suprimieron todos los soviets, éstos reaparecieron en varias oportunidades y según el autor Adamovsky (2005), mantienen aún una existencia espectral. Subsistieron en un tiempo paralelo y diferente al tiempo lineal del poder: el tiempo habitado por la potencia y el acontecimiento, el tiempo vital de la creación humana, el tiempo que sólo vemos cuando el tiempo lineal del poder se agrieta y colapsa todo lo instituido. 
Luego de Rusia, el modelo se "contagió" a la Alemania de 1918-1919, y más tarde a Hungría y a otros países europeos. Incluso en Latinoamérica hubo "soviets". Se decían que eran "soviets libres", libertad que reclamaban los insurrectos de Kronstadt en 1921, antes de ser aniquilados por el gobierno bolchevique. Por su carácter "prefigurativo" - es decir, que "anticipa" en sus propias formas democráticas y horizontales, la deliberación para un mundo libre e igualitario que desea construirse o visto desde una práctica prefigurativa del socialismo-, el ejemplo de los soviets, era un ejemplo de lucha que también inspiró a muchos de los teóricos de ideas emancipatorias, desde Anton Pannekoek entre los años de 1910 a 1920 hasta Michael Albert en nuestro tiempo (Adamovsky, 2005).

Cuando se formaron las asambleas populares en Argentina tras la rebelión del 19 y 20 de diciembre de 2001, y los editorialistas del diario La Nación exclamaron aterrados “ison soviets!", los obreros de Ivanovo-Voznesensk deben haber sonreído con orgullo en sus tumbas largamente olvidadas: su creación aún vive como ejemplo para las luchas emancipatorias, y como fantasma para sus enemigos (Adamovsky, 2005).

\section{El Consejo Popular de Cuba}

El Consejo Popular de Cuba es el órgano del sistema más vinculado a los Delegados, al pueblo y a los centros laborales; él está investido de la más alta autoridad para el desempeño de sus funciones, representando a la demarcación donde actúa y también a los órganos del Poder Popular municipal, provincial y nacional.

Luego que surgieron los Consejos Populares de forma experimental, en $1991 \mathrm{el}$ Gobierno decide extenderlos a todo el país. En la reforma de la Constitución de Cuba en julio del año de 1992, se incluyó en el capítulo XII, referente a los órganos locales del Poder Popular, el artículo 104 sobre la creación y funcionamiento de los Consejos Populares.

Artículo 104.- "Los consejos populares se constituyen en ciudades, pueblos, barrios, poblados y zonas rurales; están investidos de la más alta autoridad para el desempeño de sus funciones; representan a la demarcación donde actúan y a la vez son representantes de los órganos del Poder Popular Municipal, Provincial y Nacional".

Los Consejos Populares fueron creados con el objetivo primordial de garantizar una representación del Estado en la comunidad, que vele por la eficiencia de la producción, los servicios y asegure la participación de la población en la fiscalización y control de la actividad de las entidades estatales y privadas, a su vez, conozca las necesidades e inquietudes de los miembros y ofrezca el apoyo necesario para su solución. 


\section{CIENCIAS SOCIALES}

Está integrado por un presidente y los delegados de las circunscripciones que lo conforman. En dependencia de su complejidad y número de habitantes se pueden seleccionar, además, uno, dos y hasta tres vicepresidentes.

Posee otros integrantes como un representante designado por cada una de las organizaciones de masas del lugar y representantes de las entidades administrativas fundamentales del territorio, pero garantizando que los delegados siempre sean la mayoría.

\section{Funciones:}

- Cumplir y exigir el cumplimiento de la constitución y demás leyes del país, política que trazan los órganos superiores del Estado y los mandatos que le otorguen a estos.

- Contribuir a fortalecer la cohesión entre los delegados que integran el Consejo Popular, respaldar su trabajo y brindarles apoyo.

- Trabajar activamente para que se satisfagan las necesidades asistenciales, económicas, educacionales, culturales y sociales de la población y en la búsqueda de soluciones a los problemas planteados.

- Exigir eficiencia en el desarrollo de las actividades de producción y de servicios en las entidades enclavadas en su área de acción y apoyar en lo posible, su realización.

- Coordinar, cuando resulte necesario, las acciones de las entidades existentes en su área de acción y promover la cooperación entre ellas.

- Coadyuvar en su demarcación, al mejor desarrollo de las tareas de la defensa.

- Contribuir al fortalecimiento de la legalidad socialista y del orden interior, para los que realiza los análisis que sean necesarios y encausa las soluciones que correspondan.

- Apoyar el trabajo de prevención y atención social.

- Estimular a vecinos, trabajadores, estudiantes, combatientes, instituciones y entidades que se hayan destacado en el cumplimiento de sus deberes sociales, en el aporte a la solución de los problemas de la comunidad, o por haber alcanzado otros méritos.

Desde 1992, donde la Constitución de la República de Cuba definiera el papel de los Consejos Populares y unos 7 años aproximadamente del momento en que la Ley 91 regulara la organización y atribuciones de éstos, se considera insuficiente el conocimiento que la población y dirigentes de los diferentes sectores tienen sobre estos órganos de Poder Popular. 
La Ley 91 define al Consejo Popular como un órgano del Poder Popular, local, de carácter representativo, investido de la más alta autoridad para el desempeño de sus funciones. En cuanto a dicha autoridad, la Constitución de la República de Cuba determina que, además de representar a la demarcación donde actúan, los Consejos Populares son representantes de los órganos del Poder Popular municipal y nacional.

Estas funciones que la Constitución de Cuba y la Ley 91 les asignan a los Consejos Populares, que todas las instituciones, organizaciones, entidades y funcionarios están obligados a acatar, establecen, además, la alta jerarquía de estos órganos respecto a los demás, no solo en la demarcación donde actúan, sino también en las diferentes instancias de dirección en las que establecen relaciones de trabajo, de cooperación y coordinación. Según el Presidente de Cuba, Fidel Castro en una presentación realizada sobre la Ley 91 indica qué son los Consejos Populares:

Creo que realmente el Consejo Popular se convierte en el eslabón esencial -yo diría que era el eslabón perdido- de la dirección estatal socialista.

Si cualquier buen hombre se corrompe, cualquier buena idea se deforma por el camino, y nosotros tenemos que vigilar esta excelente idea (los Consejos Populares) para que se enriquezca y no se deforme por el camino (...) Naturalmente que una cosa son las ideas originales y otra cosa es el desarrollo de las ideas al contacto con las realidades. Ya los Consejos son hoy más que lo que habíamos concebido, tenemos que evitar que se distorsionen, que se deformen; tenemos que procurar que cumplan las ideas para las cuales se concibieron, ideas que a su vez se han desarrollado.

Decía que necesitábamos a alguien que pudiera poner fin al desorden, puesto que las empresas no podían controlar sus unidades allá abajo, ni los servicios". No veo ninguna otra forma de controlar esa multitud de instalaciones que el Estado tiene en sus distintas formas el Estado central, o las provincias, los municipios, no veo ninguna otra forma.

Nosotros nos preguntábamos: ¿Quiénes por aquí pueden ser los mejores fiscalizadores? Los Delegados de circunscripción, los Consejos Populares.

Los Delegados de circunscripción que eran piezas sueltas e impotentes, se han convertido en baluarte allí ahora, son algo y tienen poder en su área, en virtud de la existencia de los Consejos Populares. 
Los Consejos Populares, piedra angular de la participación de la comunidad en la solución de sus problemas².

El Presidente de Cuba, señala a los Consejos Populares como figuras fiscalizadoras y como pieza importante de la participación de la comunidad en la solución de sus problemas.

\section{Consejos Comunales en Venezuela}

En la propuesta de reforma constitucional, presentada en el 2007 por el Presidente Chávez, se le otorgaba rango constitucional a los Consejos Comunales como sexto componente de los poderes públicos. Se evidencia la disposición de querer integrarlos formalmente a la institucionalidad estatal. No obstante, la transferencia de competencias incluye crecientes responsabilidades de gestión de diferentes servicios públicos, cuyo voluntarismo y ausencia de planificación pudiera generar una "burocracia comunitaria" (Freitez, Nelson, 2007. p. 13).

No se registraron avances importantes en el trabajo de los Consejos Locales de Planificación Pública (CLPP), una figura que a pesar de contar con rango constitucional, ha sido solapada por los Consejos Comunales, debido a la posibilidad de estos últimos de tener relaciones directas con el poder central sin las mediaciones parroquiales, municipales y estatales establecidas en el Sistema Nacional de Planificación y Participación, del cual los CLPP forman parte. (Rivero, 2008).

Tampoco se detectaron progresos en la discusión y elaboración del Reglamento de la Ley de los CLPP, promulgada el 26.12.06, la cual establece en su artículo 32 que dicha normativa establecería la organización y funcionamiento de los Consejos Parroquiales. Asimismo, se denunció que el Consejo Nacional Electoral no ha elaborado el reglamento para su actuación en los procesos de elección de consejeros y consejeras al CLPP, como lo establece la ley (Rivero 2008, citado por Camus, 2008).

Cabe destacar que estos consejos comunales fue una propuesta de Consejo de Trabajadores presentada en la Asamblea Nacional desde el año 2007, en el marco de la Reforma Constitucional rechazada por la población en diciembre de ese año. El concepto tiene sus orígenes en las insurgencias obreras surgidas de las ruinas de la 1era. Guerra Mundial y en la oleada revolucionaria que sacudió la Europa de 19171921, con experiencias tan disímiles en Hungría, Austria, Alemania, Rusia e Italia, con precedentes en la primera $\left(1^{\circ}\right)$ revolución rusa de 1905 , donde nacieron los Consejos Obreros como modelo de autogobierno proletario, similar a la experiencia de la Comuna de París del siglo XIX.

2 Palabras del Presidente de Cuba Fidel Castro sobre la figura de los Consejos Populares. Disponible en: EcuRed: Enciclopedia cubana (2009). 
El proyecto presentado (17-05-10) resalta "Los cambios a la legislación laboral se insertan en el marco de la transición al socialismo y en la idea de que la masa obrera tome conciencia de su realidad en un esquema de izquierda...".

Los movimientos obreros del siglo XIX y XX encarnaban feroces luchas contra la sobreexplotación, contra monarquías y dictaduras de diverso orden; por ello sus objetivos se centraban en lograr la unidad nacional proletaria, la conquista de la democracia y del socialismo.

Todas las experiencias europeas han indicado la preeminencia y la autonomía inalienable de los Consejos Obreros frente al Estado, situándose el debate y divergencias entre anarquistas y marxistas ante la disyuntiva de validez de los sindicatos y su independencia ante el Partido. A la final los Consejos Obreros terminaron siendo utilizados por el Estado Soviético en manos de José Stalin desde 1924; los desnaturalizaron y los convirtieron en instrumentos del Kremlin. Tanto los sindicatos, como los consejos y los soviets eran controlados por los comisarios del PCUS y los miembros de la KGB y quien protestara le esperaba Siberia. Autores plantean que estos Consejos de Trabajadores integrados al Estado a través del Poder Popular, pretenden convertirse en figuras dentro de la sociedad denominadas: Consejos Comunales, Consejos Campesinos, Consejos Estudiantiles, dependientes entre otros.

Copiar el concepto de Consejos Obreros cuando la sociedad evolucionó, las relaciones económicas son otras y la composición de los proletarios cambió sustancialmente, la idea es adecuar esas formas de participación a las situaciones del mundo actual.

\section{Conclusiones}

La figura de los consejos comunales en Venezuela se inspira en los consejos populares creados en Cuba con rango constitucional, a diferencia de Venezuela, estos órganos de participación sólo tienen facultades de fiscalización y control de la gestión pública, por su parte en Venezuela se adicionan competencias de orden financiero, todo esto con una peculiaridad importante representada por la dependencia de la Presidencia de la República. La creación de estas figuras de participación con rango legal, crean una red comunitaria de órganos desvinculados de las parroquias, los municipios que dependen de la Presidencia de la República, que además cuenta con recursos públicos, producto entre otras circunstancias de las modificaciones de la Ley del Fondo Intergubernamental para la Descentralización y la Ley de Asignaciones Económicas Especiales, en las cuales se restan recursos que antes pertenecían a los Estado y Municipios para aumentar así los fondos destinados a los Consejos Comunales. En resumen, estos órganos de participación realizan y promueven la realización de actividades de interés general, son administradores de dineros públicos, así están obligados a llevar registros de la administración de los fondos y sus soportes, sus miembros tienen la obligación de presentar declaración jurada de su patrimonio ante la Comisión Presidencia del Poder 
Popular, al mismo tiempo que en relación a sus actuaciones tiene responsabilidad civil, penal, administrativa, de igual forma, también corresponde a los consejos ejercer directamente la gestión de políticas públicas y recibir transferencias de servicios públicos.

\section{Lista de referencias}

Adamovsky, Ezequiel (agosto 2005). La revolución rusa de 1905: El año en que nacieron los soviets. En: Encrucijadas, no. 34. pp. 1-4. Universidad de Buenos Aires. Disponible en el Repositorio Digital Institucional de la Universidad de Buenos Aires: http://repositoriouba.sisbi.uba.ar/

Camus, Albert (2008). Participación social en Venezuela durante los años 2007 y 2008 una mirada desde los DDHH. Aporte para el Informe Anual 2008 de Provea.

Ceballos, Edward, (2009). Participación Ciudadana en el marco de la Constitución de la República Bolivariana de Venezuela y los Consejos Comunales. En: Revista Provincia $N^{\circ}$ 21. Revista Venezolana de Estudios Territoriales. Universidad de los Andes. Enero-junio 2009. pp. 43-6o. Disponible en: http://www.saber.ula. ve/handle/123456789/28629

EcuRed Enciclopedia Cubana (2009). Los consejos Populares. Recuperado en: Septiembre 2015 de: http://www.ecured.cu/Consejo_Popular

Freitez, Nelson. (2007). Serie Diálogo Democrático. Alcances y Límites de la Economía Social en la Venezuela Actual. ILDIS - A.C. Acuerdo Social - Convite A.C (Ed). Caracas. 2007. pp. 20. [en línea] Disponible en: http://www.ildis.org.ve/ website/p_index.php?ids=7\&tipo=P\&vermas=92\&gt

Rivero, Amado. (2008). Análisis sobre la Reforma de la ley de los CLPP a un año y 2 meses. Sobre las fallas de la misma y la participación protagónica, su alcance, trabas y que le otorga esta ley al pueblo. Noticias Aporrea [en línea]. Disponible en: http://www.aporrea.org/poderpopular/a51652.html\&gt 